\title{
El estudio estético y del binomio identidad-alteridad (nosotros-otros) occidental
}

Daniel Montero Rodríguez

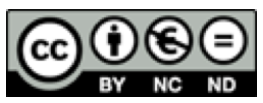

Esta obra está bajo una licencia Creative Commons

Reconocimiento-No comercial-Sin Obra Derivada 



\title{
El estudio estético y del binomio identidad-alteridad (nosotros-otros) occidental
}

\author{
Daniel Montero Rodríguez, \\ Sede de Occidente, Universidad de Costa Rica. \\ danielmont84@gmail.com
}

Recibido: 24 de abril de 2015 Aprobado:18 de febrero de 2016

\section{Resumen}

El presente artículo aborda la noción de estética como construcción sociocultural, a partir del binomio occidental de identidad-alteridad. En primera instancia, se analizan algunas propuestas teóricas de especialistas estetólogos respecto a la visión de la estética producida por el "otro" cultural (negro, indígena), según Occidente. En segundo lugar, se analiza -en forma general- el entendido "otro" frente a un "nosotros", a partir del ámbito estético.

Palabras clave: estética, cultura, identidad, alteridad, Occidente.

\begin{abstract}
This article addresses the notion of aesthetics as a socio-cultural construct, based upon the Western world binominal: identity-otherness. First of all, it analyzes some theoretical proposals from specialists in aesthetics in regards to the conception of aesthetics produced by the cultural 'other' (the black, the indigenous) according to the Western world. Secondly, the article analyzes, from a general perspective, the given of 'the other' before 'us', from the aesthetic context realm.
\end{abstract}

Key words: aesthetics, culture, identity, otherness, the Western world. 


\section{Artículos}

\section{Introducción al concepto de identidad}

Ante las distintas manifestaciones estéticas, que formaron las diferentes culturas a lo largo de la historia, se pretende estudiar la relación nosotros-otros como forma de identidad y alteridad cultural. De forma particular, se enfatiza, en estas formas culturales, las diversas estéticas étnicas: europeas, africanas o americanas. La propuesta consiste en plantear cierta percepción de identidades -ya sean espaciales o temporales- ante diversas formas de alteridad, la cual se manifiesta en dichas identidades. Este estudio se vincula, más que en la estética, con las formas como se plantean ciertos estudios históricos sobre la noción misma de estética. Así, mediante una revisión crítica sobre algunas lecturas de diversos estetólogos, se presenta ya sea la percepción de alteridad para el nosotros occidental (Europa) en una relación espacial o, en una relación temporal, la visión de nuestra identidad frente al otro en el pasado. Esto, manejando siempre la perspectiva desde la correspondencia de la estética, al enfrentar ciertas formas culturales.

Este trabajo no pretende realizar un compendio exhaustivo de lecturas, ni una descripción y caracterización de las estéticas que se desarrollan en los análisis. Tan siquiera se interesa por la percepción que se tenga respecto a las formas de creación o si los estudios son veraces o coincidentes con la realidad estética planteada por algunas culturas; por el contrario, solo confronta estudios sobre estéticas, los cuales permitan revisar el entendido de un otro frente a un nosotros, en las culturas analizadas en estos trabajos. En este sentido, el estudio posibilita confrontar los textos que conforman lo que en la historiografía se conoce como representación historiadora ${ }^{1}$ de la estética como alteridad de Occidente.

Para comprender mejor el desarrollo de este análisis, es necesario conocer el concepto de identidad, forma bajo la cual se concebirá el estudio de nosotros. Identidad es el modo de reconocimiento de una comunidad, cultura o sociedad, a través de ritos, costumbres o prácticas culturales, incluidas las manifestaciones plásticas-estéticas. La estudiosa Cristina Bloj define la identidad de una determinada sociedad de la siguiente forma: "[...] cuando hablamos de identidad hacemos referencia a una noción que remite al modo en que los sujetos y grupos sociales se reconocen en una espacialidad y una temporalidad determinada al mismo tiempo que en consecuencia de su alteridad" (2001, p.32). Cuando Bloj habla de que un grupo social se reconoce en una espacialidad y temporalidad determinada, de forma indiscutible, hace referencia al imaginario colectivo de

\footnotetext{
${ }^{1}$ Estas fases deben ser entendidas como las propone Enrique Florescano en el texto Tres pilares de la operación historiográfica (2012), cuando habla de la concepción de la historia: "Por último, encontramos la fase que Ricoeur llama representación historiadora, o sea, la configuración literaria o rescrita del discurso ofrecido al conocimiento de los lectores de historia" (p.259). Es decir, el texto final una vez escrita la historia.
} 
una sociedad, en el cual los integrantes de una nación son capaces de asimilarse como iguales según ciertas características con las que se identifican y, a su vez, adoptan alteridades con las cuales contrastar su identidad.

Ante la percepción de unidad comunitaria como un nosotros, es preciso identificarlo frente a otro, quien precisamente prescinde de los rasgos que caracterizan la identidad de cierta sociedad; así, la percepción de identidad de una cultura solo es posible ante la exclusión de su alteridad. Son las diferencias culturales las que propician la concepción identitaria de las sociedades. Esto lo establece Lidieth Garro, cuando habla al respecto:

En cuanto a la identidad, podemos definirla como «la percepción colectiva de un «nosotros» relativamente homogéneo (in-group) por la oposición a «los otros» (out-group), en función del reconocimiento de caracteres, cargos y rasgos compartidos (que funcionan también como signos o emblemas), así como de una memoria colectiva común»". (2003, p. 13)

Esta definición no solo establece con claridad el entendido de identidad, sino que indica con precisión la forma como actúa el nosotros y el otro en un binomio que opera como proceso de exclusión e interpretación social. De este modo, la visión de identidad colectiva es la que, en primera instancia, se revisará en los textos referentes a estéticas de diversas formas culturales. Asimismo, dicha visión se presenta como una perspectiva occidentalizada, la cual puede hacer alusión a esta forma de entender al resto; o sea, a los no-occidentales.

\section{La estética y el binomio identidad-alteridad}

Como primera interpretación de alteridad se introduce -lo que para el nosotros occidental (según una visión europea de la estética) - aquello que es o ha sido la manifestación estética de otro, como es el arte negro. Cómo se ha impuesto o se ha presentado esta relación es parte de lo que ha trabajado el filósofo José Jiménez, quien advierte que "El contacto de estas culturas con Occidente ha dado lugar, en algunos casos, a que ciertas tradiciones estéticas se incorporen al arte y sus instituciones. Y también a un mercado floreciente destinado al consumo turístico, como productos folclóricos, tradicionales, etc." (1996, p.41). Según este enfoque, el acercamiento entre estas distintas culturas ha dado lugar a transformaciones estéticas. No obstante, en general, el cuestionamiento que se ha establecido es ¿cuál es la visión de la estética del otro por parte del occidental?

Para Jiménez (1996) “Todos los aspectos de la cultura primitiva tendría una gran complejidad, pero al ser diferentes podían no ser comprendidos por los observadores occidentales" (1996, p. 49); es decir, la comprensión de la estética de uno sobre el otro podría no ser la correcta. Por tanto, se asume una forma estética en la concepción estética de otra manifestación y, con esto, se podría caer en un error, pues, al ser ambas diferentes, su estudio, análisis y comprensión debería ser realizado según posiciones diversas y no desde un mismo punto de vista. Uno de los mayores riesgos que se corre ante tal modo de asumir la otredad estética, es la descontextualización de dicha manifestación cultural; al respecto, explica Jiménez: "Sobre 


\section{Artículos}

lo que quiero llamar la atención es sobre la operación de descontextualización que, de forma necesaria, consciente o inconsciente, realizamos sobre objetos y representaciones de otros ámbitos culturales al incorporarlos, en el nuestro, dentro del arte" (1996, p.53). Aquí, el estudioso habla de formas conscientes o inconscientes de descontextualizar las estéticas foráneas, ya que, de manera involuntaria, se cuestiona, califica o contemplan bajo la cultura perteneciente estéticas foráneas, lo cual saca a los objetos estudiados del contexto al cual pertenecen.

A lo que se quiere llegar es a esa visión que Occidente posee de la otredad a la cual le aplica e impone, de forma -prácticamente- absoluta, una percepción analítica de la estética. Esta forma de ver generaliza, preconcibe conceptos e intenciones artísticas. Así por ejemplo, Octavio Paz habla respecto a cómo el nosotros occidental comprende, en general, otras manifestaciones culturales, ya no en relación con un arte negro, sino en una relación con una estética americana: "El arte moderno de Occidente, que nos ha enseñado a ver lo mismo una máscara negra que un fetiche polinesio, nos abrió el camino para comprender el arte antiguo de México. Así, la otredad de la civilización mesoamericana se resuelve en lo contrario: gracias a la estética moderna, esas obras tan distantes son también nuestras contemporáneas" (1977, p.46). Claro está que, para Paz, esta generalización del estudio europeo de arte sobre diferentes culturas es, de algún modo, positiva. De momento, lo que interesa es esa manera de estudiar, desde un mismo concepto, diversas creaciones estéticas.
Al presentarse la otredad con un aspecto diferente para el mundo occidental, el otro no solo se vuelve extraño, sino que, a su vez, es excluido. Octavio Paz habla del enfrentamiento cultural que se dio con el re-descubrimiento de América: "El viejo Mundo estaba regido por la tríada: tres tiempos, tres edades, tres humores, tres personas, tres continentes. América no cabía, literalmente, en la visión tradicional del mundo. Después del descubrimiento, la tríada perdió sus privilegios. No más tres dimensiones y una sola realidad verdadera: América añadía otra dimensión, la cuarta, la dimensión desconocida" (1977, p. 42). Desde esta perspectiva, la estética americana ya estaba prejuzgada no solo desde un carácter de otredad, sino de antiestética occidental.

La perspectiva que surgió para el europeo, al enfrentarse con la forma estética de la otredad mesoamericana, fue -como lo manifiesta Paz- una relación de desprecio y rechazo, no solo por el sentimiento de diferenciación, sino por el desconocimiento de este trabajo, su modo de producción técnica e ideológica. El otro era evaluado desde perspectivas foráneas a la mesoamericana, pero propias de la visión europea. Así, por ejemplo, Paz habla del historiador Ignacio Bernal, quien dejó al descubierto que el barón Alejandro de Humboldt, al revisar una escultura de una deidad aborigen, expuso su repulsión a tal estética; Paz agrega: "La presencia de la estatua terrible era insoportable" (1977, p.40). De este modo, se observa el mecanismo con el cual se desarrolla el binomio identidad-otredad, donde la identidad (Occidente) califica al 
otro según su percepción de este como alteridad (Mesoamérica), en este sentido, evalúa la estética ajena según el criterio de belleza de una cultura propia.

Por otro lado, la noción del binomio nosotros-otros no se da exclusivamente en la relación espacial de ciertas culturas o sociedades, en el mismo lapso temporal. Por el contrario, la comprensión de una cultura sobre otra se puede observar a través de una divergencia temporal, en la cual un nosotros actual, referencia una otredad del pasado; como aduce Barzuna Pérez: "[...]la búsqueda de la identidad es precisamente lo que permite una visión del mundo a través de las imágenes que configuran el gran texto cultural de América Latina [...] habría que apoyarse en el pasado para proyectar una imagen sobre el futuro" (2005, p.2). De esta manera, se pretende estudiar el pasado, pero según criterios ajenos a su temporalidad (como pasado), sino que se generan en una actualidad ajena a esta forma estética.

En la posición de una alteridad temporal que remite al pasado, por parte de una identidad contemporánea, cabe preguntarse, al igual que anteriormente se hizo con Occidente: ¿cuál es, en este caso, la visión que maneja el nosotros respecto a una otredad pasada?, ¿es, al igual que para occidente, una actitud de rechazo y desconfianza, o la representación de una posición diferente? Para Raymond Bayer, la perspectiva se maneja desde una cultura anterior a la que realiza el estudio histórico-estético; así es -hasta cierto puntoespeculativa $\mathrm{y}-$ si se quiere- inconsciente.
En palabras del autor: "Podemos representarnos la mentalidad y la sensibilidad de los hombres que han creado tales obras, incluso si esta mentalidad es inconsciente. La creación de una obra de arte cualquiera supone siempre cierta dirección de las energías del hombre, y esta dirección corresponde con gran exactitud a aquello que esperamos de la estética" (1993, p.9). Tal propuesta es de importancia no tanto por su ideología, como por el hecho de plantear el modo de ver del nosotros, como sociedad actual, la creación estética de otredades pretéritas. Presupone la noción de cierta identificación con estas y su elaboración estética.

Para estos efectos, que se vienen desarrollando sobre alteridades e identidades en lapsos histórico-temporales disímiles, el estudioso Octavio Paz ofrece una visión muy concreta y positiva sobre tal vínculo. Habla, el autor mexicano, respecto a una escultura mesoamericana que, en tiempo pasado, fue rechazada por Occidente y recluida al olvido, pero "[...] hoy ocupa un lugar central en la gran sala del Museo Nacional de Antropología consagrado a la cultura azteca. La carrera de la Coatlicue - de diosa a demonio, de demonio a monstruo y de monstruo a obra maestra- ilustra los cambios de sensibilidad que hemos experimentado durante los últimos cuatrocientos años" (1977, p.40). Estos cambios de los que habla el estudioso, son la transición por la cual el nosotros vigente en la actualidad maneja una visión más positiva sobre las estéticas mesoamericanas, sacándolas de la exclusión donde se encontraban y estudiándolas como arte (cuestión que no se aleja del todo de una percepción occidental). 


\section{Artículos}

A pesar de la actitud positiva que llega a generarse por parte del nosotros contemporáneo, como identificación con la otredad (ya sea mesoamericana, africana o cualquier otra), es -hasta cierto punto- engañoso; esto, ya que se establece sobre supuestos de sociedades que no se conocen, o que apenas se llega a comprender levemente. Todo esto lo propone Octavio Paz de la siguiente forma: "Se dice con frecuencia que esa comprensión es ilusoria: lo que sentimos ante un relieve de Palenque no es lo que sentía un maya. [...] Estamos condenados a la traducción y cada una de nuestras traducciones, trátese del arte gótico o del egipcio, es una metáfora, una transformación del original" (1977, p.45). Paz habla de una transformación del original, refiriéndose al hecho de que cambia el sentido con que se aprecia cierta estética ajena. Así, para estas sociedades antiguas, lo que hoy se denomina arte, pudo haber tenido un carácter religioso, cosmológico o mágico. Pero, desde una perspectiva contemporánea, sus creaciones representan sentidos estéticos que se asocian con concepciones actuales sobre esto.

En cuanto al cambio de sentido en la apreciación de creaciones culturales, Juan Acha expone el objetivo de ciertas creaciones mesoamericanas, proponiéndolas como un instrumento de comunicación: "Sus esculturas que representan deidades ostentan un rostro en perfil estereotipado y rodeado de símbolos e información escrita o jeroglífica de espacio y tiempo. Su profusión incurre en el barroquismo. Para ser precisos, tienen la comunicación por su objetivo principal, sin dejar de contener, por eso, una carga estética para nosotros" (1993, p.42). El autor aclara que tales obras, a pesar de su utilidad como transformaciones de información, para nosotros tiene una carga estética y caen así en una descontextualización. Se puede decir que ya no son las mismas obras; son vestigios de sociedades anteriores que hablan de un pasado extinto, pero sobre todo, son re-interpretadas. Esto da cabida a una cierta relación entre el nosotros y el otro, de temporalidad disímiles.

En este sentido, se puede asumir que la percepción estética occidental, como identidad cultural fija, se presenta como paradigma para el estudio de otras formas estéticas que se asumen como alteridades de tal identidad. Esto es sugerido por el estudioso Ticio Escobar como una problemática de la teoría del arte: "El problema es que estos requerimientos, específicos de un modelo histórico (el moderno), pasan a funcionar como canon universal de toda producción artística y como argumento para descalificar aquella que no se adecuase a sus cláusulas" (2011, p.5). Como propone Escobar, no solo es un problema al establecer una sola cultura y su identidad como canon sino que plantea, a través de esta, una descalificación de las estéticas que no se ajustan a este.

Por tales motivos, el paradigma artístico que presenta Occidente para el resto de estéticas del mundo, no solo debe descentralizarse sino que se debe validar la variedad de alteridades y sus estéticas, es decir, debe validarse la variedad de identidades, más que 
considerar la identidad occidental y al resto del mundo como sus alteridades. Asimismo, en cuanto a la producción contemporánea de las diferentes estéticas del mundo, se debe observar la creación artística como una producción validada, ya no por occidente, sino por el conjunto de culturas estéticas que existen. Como propone el estudioso Gerardo Mosquera al referirse al trabajo del artista cubano Wifredo Lam:

Más que ante una omisión, estamos frente a una ceguera del discurso eurocéntrico, incapaz de distinguir que en este arte no se trata ya de Occidente asimilando en su interés formas y recursos de las culturas subalternas: en él se vislumbra a No Occidente comenzando a expresarse mediante los mecanismos artísticos internacionalizados por Occidente y capaces de acción efectiva en el mundo de hoy. (2002, p. 247)

De esta manera, el estudioso propone una estética que como otredad a la identidad occidental logra posicionarse y validarse como arte, fuera de los cánones eurocéntricos, pero dentro de sus postulados; en este sentido deja de ser alteridad de Occidente y como otredad validad su propia identidad latinoamericana.

Para finalizar, se puede entender como el estudio de distintas alteridades culturales a través de una perspectiva occidental, no solo proyecta un problema en el estudio del pasado como historia, sino que a su vez, implica un problema de descontextualización temporal y espacial, es decir, una correcta interpretación de la estética requiere de la interdisciplinariedad e intercultural en el estudio histórico del dicho concepto. Como presenta el estudioso Antonio Pizza:

La historia, en definitiva, ya no puede remitirse a un tiempo unitario, porque el tiempo y sus ritmos son de hecho una construcción nuestra. La necesaria variedad de las fuentes documentales refleja la pluralidad de la vida, mientras el lugar de la interpretación se configura como una verdadera red en la que las posibles historias se multiplican, sin poder jamás alcanzar una síntesis totalizadora. (1989, p.117)

Es decir, el estudio de la estética de las otredades se ve parcializado por la perspectiva occidental, generando una percepción sesgada de las imágenes estudiadas en la historia. De tal manera, la verdadera concepción de las diversas imágenes en distintas culturas es incomprensible y la discusión estética que se genera desde occidente se considera vano, tanto como estudio histórico como en su valor artístico, social y cultural.

\section{Conclusiones}

Se puede hablar de cierto efecto de descontextualización, en el cual se cae al tomar instrumentos teóricos (como son los occidentales) para evaluar o medir formas culturales distintas (otredades) a las propias; más aún, conociendo el efecto que estas tuvieron al ser aplicadas por los mismos (Occidente) sobre otras (arte negro), en temporalidad y espacialidad concordante. Mucho mayor cuidado 


\section{Artículos}

se debería tener al estudiar estéticas pasadas. Para esto, es necesario mencionar a Juan Acha, quien habla sobre el estudio estetológico:

Sin lugar a dudas, la clasificación estética que nos ocupa, es evolucionista y, por eso, propia de nuestra perspectiva diacrónica, pero completamente ajena a la perspectiva sincrónica de cada generación paleoamericana. El error no está en aplicar criterios occidentales actuales en el estudio de las estéticas del pasado y de otras culturas, pues por ahora solo cantamos con el cuerpo occidental de ideas para este fin; todavía no hemos producido las requeridas pos nuestras realidades estéticas del pasado. La falla está en limitarse exclusivamente a los criterios foráneos desde nuestra realidad. Sobre todo, incurre en un desacierto garrafal cuando atribuye tales criterios a los hombres del pasado y otras culturas. (1993, p.27)

Como explica este autor, el error no está en la utilización de otros instrumentos para estudiar ciertas formas culturales. El error es quedarse solo con estos y no abordar nuevos o diferentes medios para realizar este trabajo. El autor propone conocer el trabajo estético de culturas ajenas a la perteneciente; el cual debe hacerse desde la mirada ingenua y pura, procurando no establecer criterios estereotipados y establecidos, que deformen la objetividad del análisis.

Por otra parte, un medio adecuado con el cual se evitaría incurrir en una descontextualización, es precisamente definir y establecer los modos de vida de estas sociedades.
Este paso genera (casi de modo especulativo) una contextualización cultural sobre la que se podría realizar, de forma más asertiva y propia, un estudio sobre las estéticas que realizaban. Como aclara Acha: "Pero como estetólogos hemos de intentar reconstruir su contexto sociocultural, con ayuda de los conocimientos científicos-sociales existentes y las hipótesis posibles. Para ser precisos, necesitamos renunciar a las habituales descontextualizaciones de los análisis occidentales del arte, como si este fuese una sucesión de objetos y no un fenómeno sociocultural amplio y complejo" (1993, p.29). De este modo, se procuraría ir desarrollando, poco a poco, un entendido más autóctono o propio sobre cómo abordar la estética y ciertos estilos de producción cultural. Asimismo, establecerá estableciendo criterios con los cuales analizar los estudios histórico-estéticos, alejándose, de ideologías rígidas y totalizadoras.

Se puede establecer un vínculo en el cual el nosotros busca investigar las otredades, razonando sobre sus procesos sociales que, intrínsecamente, conllevan un proceso comparativo entre ambas. En conclusión, se puede decir que, -para entender la estética de una sociedad expuesta como alteridad de un nosotros como identidad social y cultural,- es preciso conocer las redes sociales que contextualizan, a su vez, las formas de producción cultural donde se tejen los productos estéticos que son objeto de estudio. Se entiende, entonces, cómo conocer el contexto socio-cultural es conocer las representaciones estéticas de quienes las produjeron. En palabras de Octavio Paz: "El estilo no es el 
hombre: el estilo es la sociedad" (1977, p.60). El estudio de las diversas estéticas del mundo debe realizarse bajo la mirada variada de criterios y posturas que validen y analicen más críticamente y no que juzguen bajo cánones artísticos autoritarios.

En este sentido, el papel del dato histórico es relativo en la medida que funciona como base informativa para la construcción de las críticas estéticas. Es decir, las estéticas consideradas alteridades de Occidente generan un dato histórico que debe ser evaluado bajo el velo de diversas disciplinas que estudien distintos puntos de esas culturas, como sostiene Pizza: "la «comprensión» del pasado, entonces, no es en absoluto una práctica de constatación científica de una supuesta verdad de los hechos, sino una apertura de posibilidades; es decir, una creación de visiones del mundo según la experiencia propia del arte, de la religión, de la filosofía y de la política" (2000, p.115); por tanto, se deben validar los diversos estudios que surjan sobre las diferentes estéticas del mundo, mediante su estudio crítico y no solo asimilar como absoluto un paradigma crítico elaborado desde y para Occidente.

\section{Referencias}

Acha, J. (1993). Las culturas estéticas de América Latina. México: Universidad Nacional Autónoma de México.
Barzuna-Pérez, G. (2005). Cultura artística y popular en Costa Rica: 1950-2000. San José: EUCR.

Bayer, R. (1993). Historia de la estética. México: Fondo de Cultura Económica.

Bloj, C. (2001). De cuando la "ficción" supera la "realidad": apuntes sobre la identidad nacional costarricense. I parte. Revista de filosofía, 97:3-41.

Escobar, T. (2011). Arte indígena: el desafío de lo universal. En: Una teoría del arte desde América Latina. Madrid: Turner.

Florescano, E. (2012). Tres pilares de la operación historiográfica. En: La función social de la historia. México: Breviarios del Fondo de Cultura Económica.

Garro-Rojas, L.(2003). Diario La nación discurso editorial y discursos de identidad nacional 1946-1949, 1979-1982. San José: Tesis de Maestría.

Jiménez, J. (1996). Las raíces del arte: el arte etnológico. Madrid: Alianza Editorial.

Mosquera, G.(2002I. Modernidad y africanía: Wifredo Lam en su isla. En: Wifredo Lam: la cosecha de un brujo. La Habana: Editorial Letra Cubanas.

Paz, O. (1977). Los privilegios de la vista. México: Fondo de Cultura Económica.

Pizza, A. (2000). La construcción del pasado. España: Celeste Ediciones. 